\title{
Boost converter with combined control loop for a stand-alone photovoltaic battery charge system
}

Mira Albert, Maria del Carmen; Knott, Arnold; Thomsen, Ole Cornelius; Andersen, Michael A. E.

Published in:

IEEE 14th Workshop on Control and Modeling for Power Electronics

Publication date:

2013

Link back to DTU Orbit

Citation (APA):

Mira Albert, M. D. C., Knott, A., Thomsen, O. C., \& Andersen, M. A. E. (2013). Boost converter with combined control loop for a stand-alone photovoltaic battery charge system. In IEEE 14th Workshop on Control and Modeling for Power Electronics IEEE.

\section{General rights}

Copyright and moral rights for the publications made accessible in the public portal are retained by the authors and/or other copyright owners and it is a condition of accessing publications that users recognise and abide by the legal requirements associated with these rights.

- Users may download and print one copy of any publication from the public portal for the purpose of private study or research.

- You may not further distribute the material or use it for any profit-making activity or commercial gain

- You may freely distribute the URL identifying the publication in the public portal 


\title{
Boost Converter with Combined Control Loop for a Stand-Alone Photovoltaic Battery Charge System
}

\author{
Maria C. Mira, Arnold Knott, Ole C. Thomsen, Michael A. E. Andersen \\ Dept. Electrical Engineering \\ Technical University of Denmark \\ Ørsteds Plads, 349. Kongens Lyngby, Denmark \\ mmial@elektro.dtu.dk_akn@elektro.dtu.dk_oct@elektro.dtu.dk_ma@elektro.dtu.dk
}

\begin{abstract}
The converter control scheme plays an important role in the performance of maximum power point tracking (MPPT) algorithms. In this paper, an input voltage control with double loop for a stand-alone photovoltaic system is designed and tested. The inner current control loop with high crossover frequency avoids perturbations in the load being propagated to the photovoltaic panel and thus deviating the operating point. Linearization of the photovoltaic panel and converter state-space modeling is performed. In order to achieve stable operation under all operating conditions, the photovoltaic panel is linearized at the maximum power point (MPP) and at the voltage and current source regions. A settling time under $1 \mathrm{~ms}$ is obtained which allows fast MPP tracking implementation.
\end{abstract}

Index Terms: Photovoltaic, battery, MPPT, averaged smallsignal modeling, linearized PV panel.

\section{INTRODUCTION}

Renewable energies have become more important in the last decades due to the fact that fossil fuel reserves are being depleted together with the awareness of global warming and climate change. In the last years, solar energy has become one of the fastest growing technologies mainly because the Sun is the most abundant source of energy currently available and is unlimited, clean and free.

Solar cells combined with a storage element in a standalone system can be used as a self-sustained power source for all kind of electrical powered applications. An off grid system eliminates the cost of cables, which is very interesting for powering up systems at remote locations, where cabling is challenging and expensive. Moreover, it is also relevant in urban areas where, digging, construction, reconstruction, etc. is extremely costly.

A photovoltaic cell is basically a p-n junction that generates current under the effect of solar irradiation [1]. Due to its non-linear behavior, a maximum power point tracking (MPPT) algorithm that continuously tracks the maximum instantaneous power is required. The importance of the maximum power point seeking relies on the low energyconversion efficiency of photovoltaic panels. Many MPPT algorithms have been developed [2], [3] and several publications can be found in the literature presenting improvements on the classical algorithms [4], [5], [6]; however, less attention has been given to the converter control technique. Nevertheless, the performance of the MPPT will depend on the ability of the converter to regulate the operating point of the photovoltaic panel, which is determined by the control strategy [7]. Both voltage and current of the photovoltaic panel are usually taken as the control variable in order to regulate the converter operating point. Ideally, the control variable should be constant or present small variations over time. However, output current and voltage of the photovoltaic panel are time variant with changes of irradiation and temperature. The output current of a photovoltaic panel shows a linear dependence with the photogenerated current and, therefore, varies strongly with changes of irradiation. On the contrary, due to the logarithmic dependence of the voltage with the photogenerated current, the PV voltage does not present such a strong variation with irradiation changes. However, the output voltage varies with temperature changes, while the current is less affected. Regardless, temperature has slow dynamics compared to irradiation variations (e.g. due to cloudy atmospheric conditions). The aforementioned arguments make PV voltage regulation preferred over current regulation [8].

This paper presents a control scheme based in a double control loop, where the output voltage of the PV panel is controlled by the mean value of the inductor current. Fig. 1 shows the case study where a boost converter is connected to a photovoltaic panel at the input and a battery at the output.

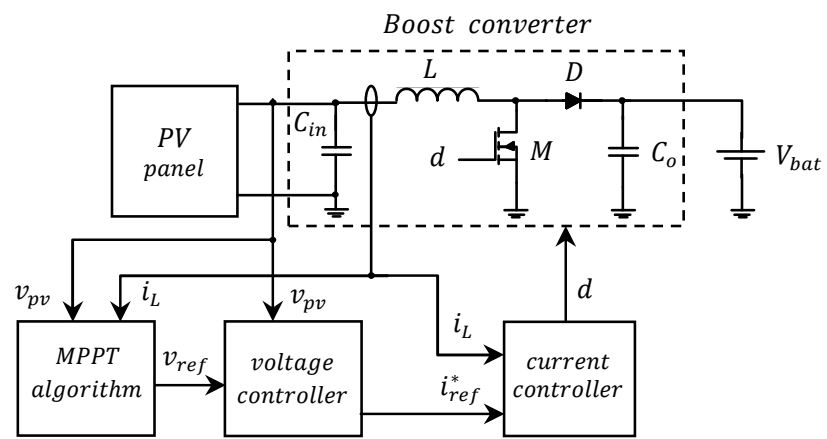

Figure 1. Block diagram of the system with the proposed control strategy 
The inner current loop controls the inductor current and the outer voltage loop controls the converter input voltage by setting the mean value of the inductor current. This configuration allows decoupling the PV panel operating conditions from perturbations at the load. In this case, the converter is loaded with batteries and the output voltage can be considered constant. However, if a grid connected battery charger or inverter is inserted in the system, perturbations with the grid frequency can propagate to the PV panel side altering the operating point. The inner current loop with higher crossover frequency than the outer voltage loop will present a higher error reduction at this frequency, avoiding propagation of these perturbations to the PV panel side.

\section{PV PANEL AND CONVERTER MODELING}

\section{A. Photovoltaic panel modeling}

Photovoltaic devices present a non-linear $I-V$ characteristic. Fig. 2 shows the single diode equivalent model of a solar cell neglecting the shunt resistance. Equation (1) describes the output current of a photovoltaic cell, where $I_{p h}$ represents the photogenerated current (directly proportional to the Sun irradiation), $I_{o}$ is the diode's dark saturation current, $V_{t}=A k T / q$ is the thermal voltage, $A$ is the diode ideality factor, $k$ is Boltzmann's constant $\left(1.380 \cdot 10^{-23} \mathrm{JK}^{-1}\right)$, $T[K]$ is the $p-n$ junction temperature and $q$ is the electron charge $\left(1.602 \cdot 10^{-19} C\right)$. Fig. 3 shows the $I-V$ curve of a PV panel where the maximum power point is located at the knee of the curve given by the points $V_{m p}$ and $I_{m p}$. For $V_{p v}<V_{m p}$, the PV panel operates as a current source while for $V_{p v}>$ $V_{m p}$ the panel acts as a voltage source [9]. In order to include the input source as a part of the converter, a linearized model of the photovoltaic panel is required.

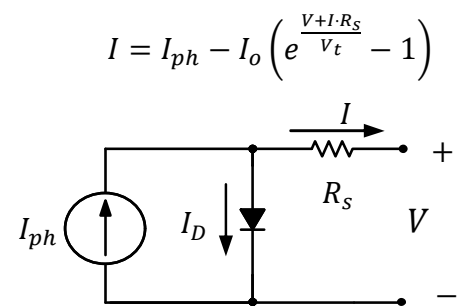

Figure 2. Single diode with series resistance equivalent model

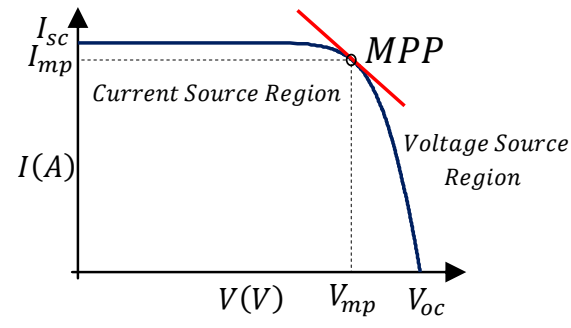

Figure 3. $I-\mathrm{V}$ characteristic of a PV panel

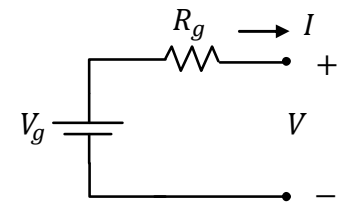

Figure 4. Equivalent linearized model of a PV panel
Based in [9] the PV panel can be linearized by using the derivative of the non-linear curve (1) at the linearization point, as shown in (2). The linear model is described by the tangent line to the $I-V$ curve at this point (3).

$$
\begin{gathered}
g=\left.\frac{d I}{d V}\right|_{\substack{V=V_{m p} \\
I=I_{m p}}}=-\frac{I_{O}}{V_{t}} \cdot e^{\left(\frac{V_{m p}+I_{m p} \cdot R_{s}}{V_{t}}\right)} \\
I=\left(-g \cdot V_{m p}+I_{m p}\right)+g \cdot V
\end{gathered}
$$

Fig. 4 shows the linear equivalent circuit of the photovoltaic panel. It is represented by an equivalent voltage source (4) and a series resistance (5), obtained by particularizing (3) at $I=0$ and $V=0$, respectively.

$$
\begin{array}{r}
V_{g}=V_{m p}-\frac{I_{m p}}{g} \\
R_{g}=-\frac{1}{g}
\end{array}
$$

The model is valid at the linearization point and it is a good aproximation for obtatining a small signal model of the photovoltaic panel. It is desired to always operate at the maximum point; however, it is possible that the PV panel changes its operation point to the current or voltage source region. The dynamic behavior of the overall system, photovoltaic panel and power stage, will strongly depend on the operating point of the panel. In order to design the control loop and ensure stability of the converter under all the operating conditions, the PV panel is also linearized at the current and voltage source regions by using (2) and (3).

\section{B. Boost converter modeling}

In this section state-space average modeling [10] of boost converter is performed. The model includes parasitic resistances of the reactive elements, the MOSFET's on resistance and the diode forward voltage drop. Since the converter acts as a battery charge system, the load is modeled as an ideal voltage source in series with the battery dynamic resistance. In order to obtain a linear model, the converter is taken as an equivalent circuit for the charging and discharging states. Each switching state is expressed in terms of state space equations, (6) and (7). Note that the output equation (7) is not used since the controlled variables, inductor current (inner control loop) and input voltage (outer control loop), are state variables.

$$
\begin{gathered}
\frac{d x(t)}{d t}=A x(t)+B u(t) \\
y(t)=C x(t)+D u(t)
\end{gathered}
$$

Fig. 5 and Fig. 6 show the equivalent linear circuits during the charging and discharging states. The equivalent resistance, $r_{e q}$, is the series combination of the inductor parasitic resistance and the MOSFET's on resistance, $r_{e q}=r_{L}+r_{M}$.

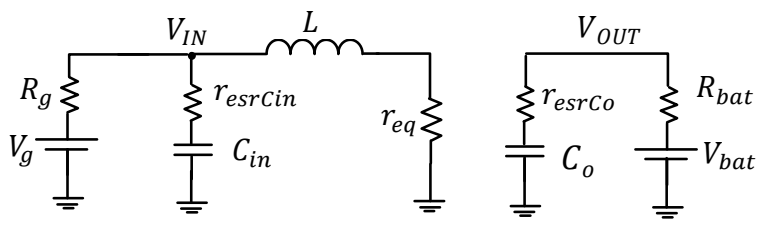

Figure 5. Equivalent boost converter during the charging state 


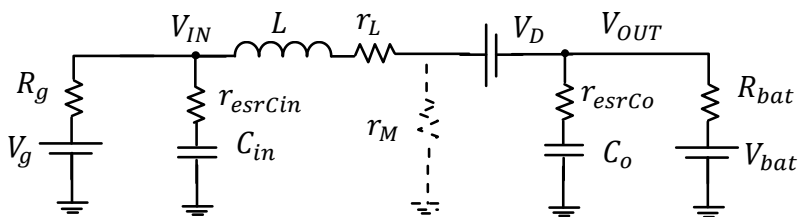

Figure 6. Equivalent linear circuit during the discharging state

The dynamic equations corresponding to the charging state are obtained by evaluating the derivatives of the inductor and the input and output capacitor of Fig. 5 as shown in (8), (9) and (10).

$$
\begin{gathered}
\frac{d i_{L}(t)}{d t}=\frac{V_{I N}(t)-i_{L}(t) \cdot r_{e q}}{L} \\
\frac{d v_{C_{i n}}(t)}{d t}=\frac{V_{I N}(t)-v_{C_{\text {in }}}(t)}{C_{\text {in }} \cdot r_{\text {resrCin }}} \\
\frac{d v_{C_{O}}(t)}{d t}=\frac{V_{\text {OUT }}(t)-v_{C_{O}}(t)}{C_{O} \cdot r_{\text {esrCo }}}
\end{gathered}
$$

Rewriting the dynamic equations (8), (9) and (10) in statespace form as (11) results in (12), shown at the bottom of the page.

$$
\frac{d x(t)}{d t}=A_{1} x(t)+B_{1} u(t)
$$

The dynamic equations during the discharging state are found by evaluating the derivatives of the state variables of Fig. 6 as given in (13), (14) and (15).

$$
\begin{gathered}
\frac{d i_{L}(t)}{d t}=\frac{V_{I N}(t)-i_{L}(t) \cdot r_{L}-V_{D}-V_{\text {OUT }}(t)}{L} \\
\frac{d v_{C_{i n}}(t)}{d t}=\frac{V_{I N}(t)-v_{C_{i n}}(t)}{C_{\text {in }} \cdot r_{\text {esrCin }}} \\
\frac{d v_{C_{O}}(t)}{d t}=\frac{V_{\text {OUT }}(t)-v_{C_{O}}(t)}{C_{O} \cdot r_{\text {esr } C o}}
\end{gathered}
$$

Expressions of $V_{I N}$ and $V_{\text {OUT }}$ for each subinterval can be found by applying Kirchhoff's laws on the corresponding equivalent linear circuit.

Expressing (13), (14) and (15) in the matrix form given in (16) results in (17), shown at the bottom of the page.

$$
\frac{d x(t)}{d t}=A_{2} x(t)+B_{2} u(t)
$$

The state and input matrixes are averaged over a period by multiplying the state and input matrixes by the two switched intervals' duty cycle.

$$
\begin{aligned}
& A=A_{1} \cdot d+A_{2} \cdot(1-d) \\
& B=B_{1} \cdot d+B_{2} \cdot(1-d)
\end{aligned}
$$

After averaging, the system is perturbed around a quiescent operating point $(X+\hat{x}, D+\hat{d}, U+\hat{u})$ where $X \gg$ $\hat{x}$, and linearized by neglecting the second order terms. Applying the Laplace transform and separating the dc and ac part of the linearized model, the steady-state operating point (20) and the dynamic or small-signal model (21) are obtained.

$$
\begin{gathered}
X=-A^{-1} \cdot B \cdot U \\
\dot{\hat{x}}=A \cdot \hat{x}+B \cdot \hat{u}+\left[\left(A_{1}-A_{2}\right) X+\left(B_{1}-B_{2}\right) \cdot U\right] \cdot \hat{d}
\end{gathered}
$$

The control transfer functions are defined for small variations of the input matrix $(\hat{u})$ equal to zero. The solution of the state variable is given by (22).

$$
\hat{x}=(s I-A)^{-1} \cdot\left[\left(A_{1}-A_{2}\right) X+\left(B_{1}-B_{2}\right) U\right] \cdot \hat{d}
$$

The duty cycle-to-inductor current transfer function (23) is used in the inner control loop and relates the small variations of the inductor current and the control variable $d$.

$$
G_{i d}(s)=\left.\frac{\hat{\iota}_{L}(s)}{\hat{d}(s)}\right|_{\widehat{u}(s)=0}
$$

In the outer control loop the controlled variable is the input voltage while the control variable is the inductor current. The transfer function from inductor current to input voltage is given by (24).

$$
G_{v i}(s)=\frac{G_{v d}(s)}{G_{i d}(s)}=\frac{\left.\frac{\hat{v}_{c i n}(s)}{\hat{d}(s)}\right|_{\widehat{u}(s)=0}}{\left.\frac{\hat{i}_{L}(s)}{\widehat{d}(s)}\right|_{\widehat{u}(s)=0}}=\frac{\hat{v}_{C i n}(s)}{\hat{\imath}_{L}(s)}
$$

In order to validate the calculated transfer functions, the mathematical model obtained by state-space modeling is plotted using MATLAB and compared with LTspice simulations. The photovoltaic panel specifications are presented in Table I. Table II shows the equivalent voltage and resistance of the linearized panel for the three different areas of the $I-V$ curve $-\mathrm{MPP}$, voltage and current source regions.

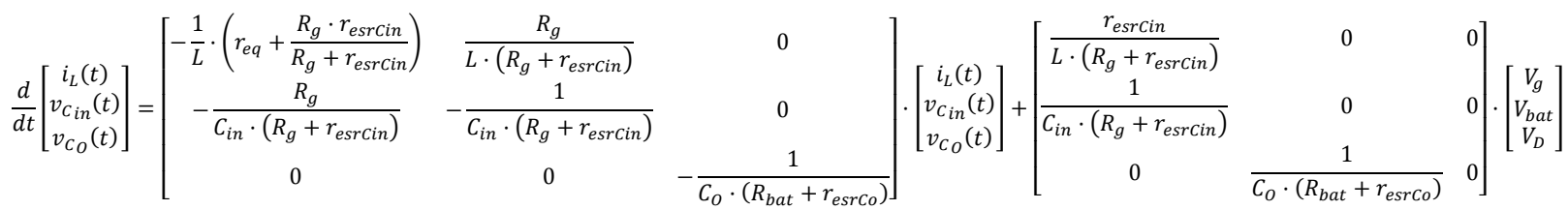

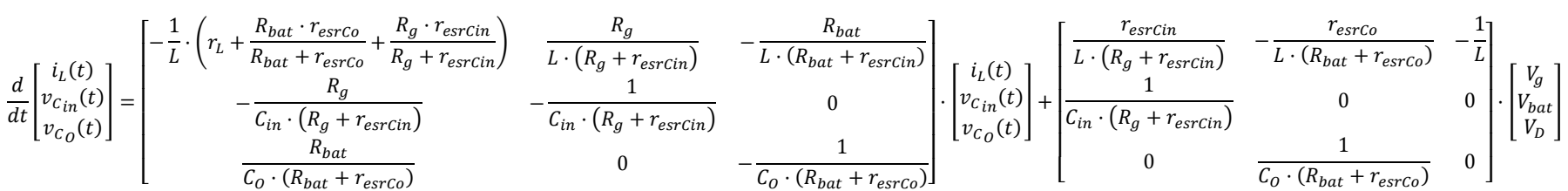


TABLE I

PV PANEL SPECIFICATIONS @ STC

\begin{tabular}{cc}
\hline \hline$P_{\max }$ & $104.4 \mathrm{~W}$ \\
$V_{m p}$ & $18 \mathrm{~V}$ \\
$I_{m p}$ & $5.8 \mathrm{~A}$ \\
$V_{o c}$ & $22.1 \mathrm{~V}$ \\
$I_{s c}$ & $6.3 \mathrm{~A}$ \\
\hline \hline
\end{tabular}

TABLE II

LINEARIZED PV EQUIVALENT VOLTAGE AND RESISTANCE

\begin{tabular}{ccc}
\hline & $V_{g}$ & $R_{g}$ \\
$M P P$ & $35.78 \mathrm{~V}$ & $3.07 \Omega$ \\
Voltage Source Region & $22.1 \mathrm{~V}$ & $0.306 \Omega$ \\
Current Source Region & $796.9 \mathrm{~V}$ & $124.7 \Omega$ \\
\hline \hline
\end{tabular}

TABLE III

PARAMETERS OF THE CONVERTER

\begin{tabular}{cc}
\hline \hline Battery Voltage $V_{\text {bat }}$ & $28 \mathrm{~V}$ \\
Inductor $L$ & $48.15 \mu \mathrm{H}$ \\
Capacitor $C_{\text {in }}$ & $40 \mu \mathrm{H}$ \\
Capacitor $C_{O}$ & $40 \mu \mathrm{H}$ \\
MOSFET & IPP039N04L \\
Diode & DSB10I45PM \\
Switching frequency & $100 \mathrm{kHz}$ \\
\hline \hline \multicolumn{2}{c}{ TABLE IV } \\
CONVERTER PARASITIC RESISTANCES \\
\hline \hline$r_{L}$ & $8.9 \mathrm{~m} \Omega$ \\
$r_{M}$ & $3.9 \mathrm{~m} \Omega$ \\
$r_{\text {esrCin }}$ & $3 \mathrm{~m} \Omega$ \\
$r_{\text {esrCo }}$ & $3 \mathrm{~m} \Omega$ \\
$R_{\text {bat }}$ & $10 \mathrm{~m} \Omega$ \\
\hline \hline
\end{tabular}

The simulations are performed using the parameters of the converter shown in Table III and the parasitic resistances of Table IV, for the PV panel linearized at the MPP. Fig. 7 and Fig. 8 show the gain and phase plots of the converter duty cycle-to-inductor current transfer function $\left(G_{i d}\right)$ and the inductor current-to-input voltage transfer function $\left(G_{v i}\right)$. It can be observed that the calculated transfer functions obtained by state-space modeling show very good match with the simulations. The duty cycle-to-inductor current transfer function is a second order system formed by the inductor and the input capacitor. However, a zero formed by the equivalent input resistance $R_{g}$ and the input capacitor makes the system to behave as a first order system. On the other hand, the inductor current-to-input voltage transfer function is a first order system with a pole formed by the input capacitor and the equivalent input resistance $R_{g}$. Note that this transfer function presents a $-180^{\circ}$ phase shift.

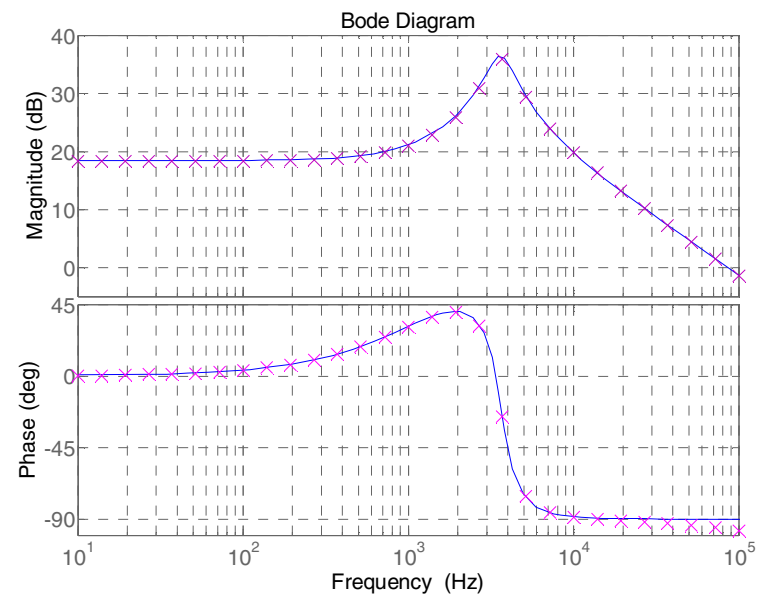

Figure 7. Duty cycle-to-inductor current $\left(G_{i d}\right)$ transfer function calculated (blue line) and simulated (crosses)

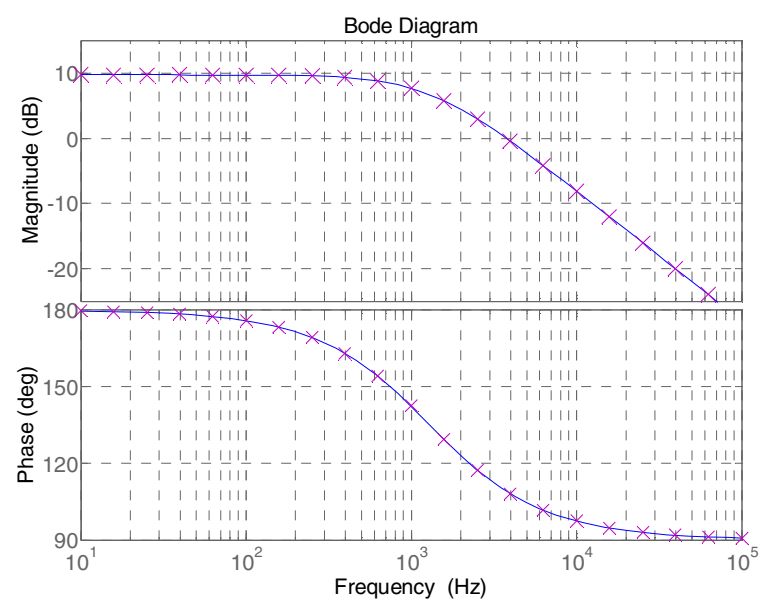

Figure 8. Inductor current-to-input voltage $\left(G_{v i}\right)$ transfer function calculated (blue line) and simulated (crosses)

\section{CONTROL LOOP DESIGN}

The proposed control scheme is a double loop control [7] where the output voltage of the photovoltaic panel, $v_{p v}$, is controlled by the mean value of the inductor current, $i_{L}$. Fig. 9 shows the simplified block diagram of the control strategy where $C_{v}$ represents the voltage compensation, $G_{i_{-} c l}$ the closed loop transfer function of the inner current control loop, $G_{v i}$ the converter inductor current-to-input voltage transfer function and $H_{v}$ the input voltage measurement gain. Fig. 10 shows the block diagram of the inner current control loop $\left(G_{i, c l}\right)$ where $C_{i}$ denotes the current compensation, $P W M$ the pulse-width modulator, $G_{i d}$ the converter duty cycle-to-inductor current transfer function and Diff.Amp. and Current Sensor the current measurement gain.

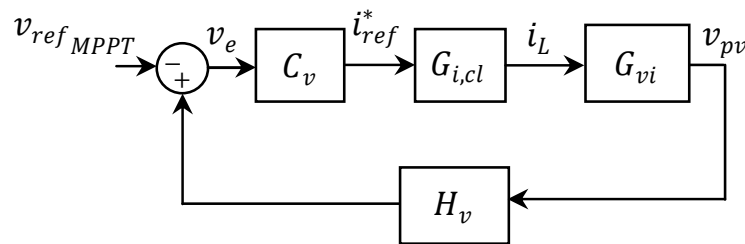

Figure 9. Simplified block diagram of the control scheme 


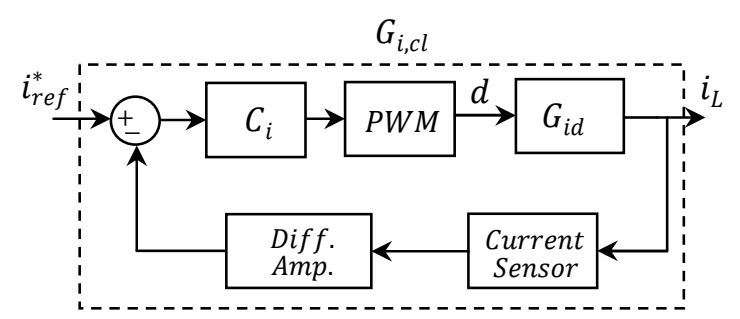

Figure 10. Inner current control loop block diagram

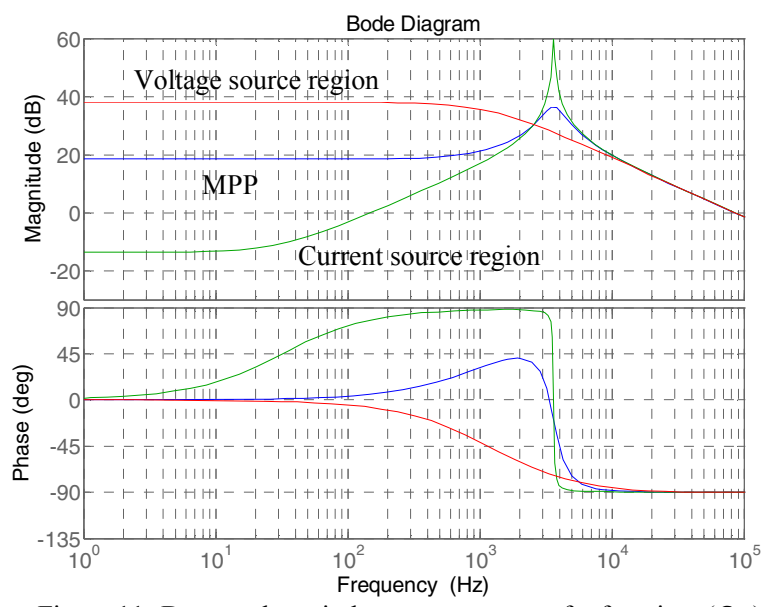

Figure 11. Duty cycle-to-inductor current transfer function $\left(G_{i d}\right)$ for different operating point of the PV panel

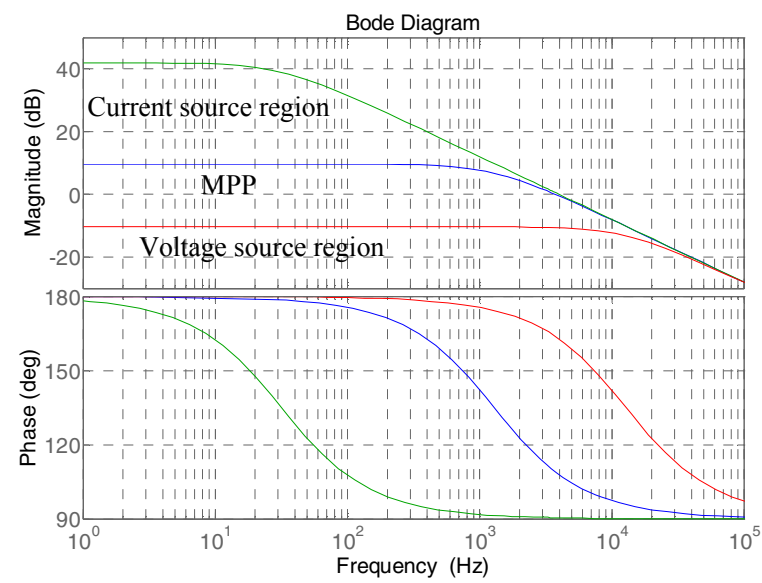

Figure 12. Inductor current-to-input voltage transfer function $\left(G_{v i}\right)$ for different operating point of the PV panel

Fig. 11 shows the duty cycle-to-inductor current transfer function for the three different operating points defined in Table II. Blue line corresponds to the transfer function when the PV panel operates at the maximum power point; green line when it operates in the current source region and red line in the voltage source region. In the current source region, where the equivalent input resistance $R_{g}$ is high, the zero formed by $R_{g}$ and the input capacitor moves to a lower frequency and the quality factor of the second order system formed by $L, C_{i n}$ and $R_{g}$ increases. Moreover, the dc gain, inversely proportional to the input resistance $R_{g}$, is below zero $\mathrm{dB}$ meaning that the PV panel behaves as a current source and the controlability of the inductor current is poor. In the voltage source area the dc gain increases due to the decrease in the equivalent input resistor. The poles, that were a pair of complex poles at the resonant frequency, split and the system shows an overdamped response. Fig. 12 shows the inductor current-to-input voltage transfer function for the three different operating points of the PV panel. The plant is a first order system with a pole formed by the input capacitor and the equivalent input resistance $R_{g}$. In the voltage source region where the equivalent resistance is low, the pole appears at high frequency and it moves to lower frequencies as the resistance increases. The dc gain, directly proportional to the input equivalent resistance, is low at the voltage source region and it increases as the operating point moves towards the current source region. In the voltage source region, where the PV panel behaves as an ideal voltage source, the low dc gain indicates that variations in the inductor current have small effect in the panel output voltage.

Fig. 13 shows the power stage and the control loop circuitry with defined blocks for the current and voltage loops. Table V shows the designed component values.

The design process starts by designing the inner current control loop (Fig. 10). The current sensor used is a Hall effect sensor from Allegro MicroSystems with a peak current of $\pm 12.5 \mathrm{~A}$ and sensibility of $56 \mathrm{mV} / \mathrm{A}$. A differential amplifier is used to remove the offset introduced by the current sensor and to adapt the signal level of the measured current. The dc gain introduced by the differential amplifier is given by (29).

$$
G_{\text {Diff Amp }}=\left(1+\frac{R_{4}}{R_{3}}\right) \cdot \frac{R_{6}}{\left(R_{5}+R_{6}\right)}
$$

The current loop compensation (30) is formed by an integrator and a zero placed at the resonant frequency of the plant transfer function $\left(G_{i d}\right)$.

$$
C_{i}=\frac{1}{R_{7} C_{1}} \cdot \frac{1}{S} \cdot\left(1+R_{8} C_{1} s\right)
$$

The current loop gain is determined by (31), where $1 / \mathrm{Vm}$ is the $P W M$ gain and $V m$ the modulator triangular peak value.

$$
T_{i}=C_{i} \cdot \frac{1}{V m} \cdot G_{i d} \cdot G_{D i f f A m p} \cdot G_{C S}
$$

Fig. 14 shows the current loop gain for the three different points of the PV curve. The loop is closed at $5.56 \mathrm{kHz}$ for the MPP point and the current source region. The phase margin is $66^{\circ}$ and $57^{\circ}$ respectively. In the voltage source region the crossover frequency decreases down to $4 \mathrm{kHz}$ with a phase margin of $62^{\circ}$.

The inner current closed loop transfer function $G_{i, c l},(32)$, is required for the design of the outer voltage loop. Note that the current-error amplifier transfer function $\left(C_{i}\right)$ differs depending if it is obtained from the input (negative leg) or the reference (positive leg) with a " +1 " term.

$$
G_{i, c l}=\frac{\left(1+C_{i}\right) \cdot \frac{1}{V m} \cdot G_{i d}}{1+C_{i} \cdot \frac{1}{V m} \cdot G_{i d} \cdot G_{\text {Diffamp }} \cdot G_{C S}}
$$




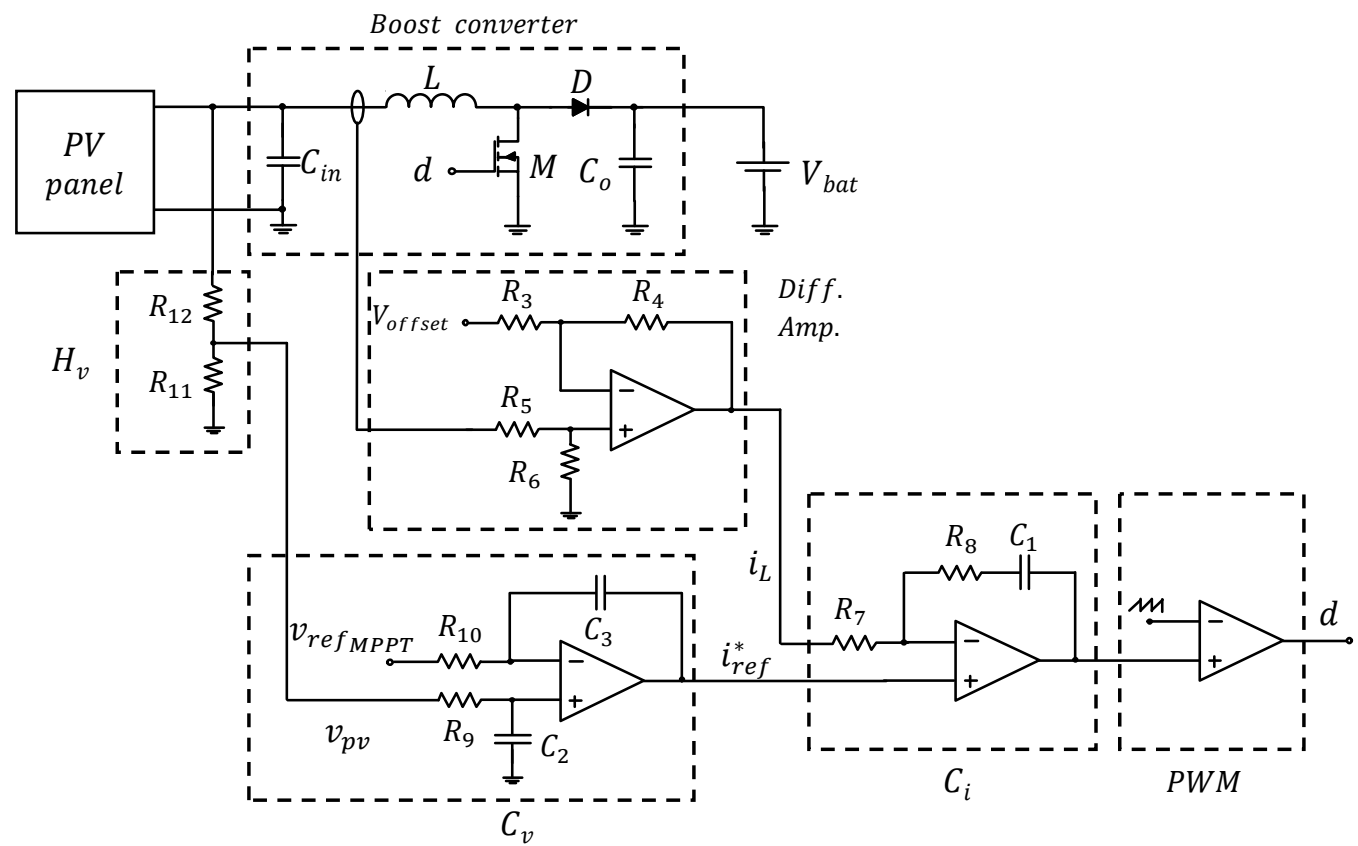

Figure 13. Boost converter and combined control loop circuitry schematic

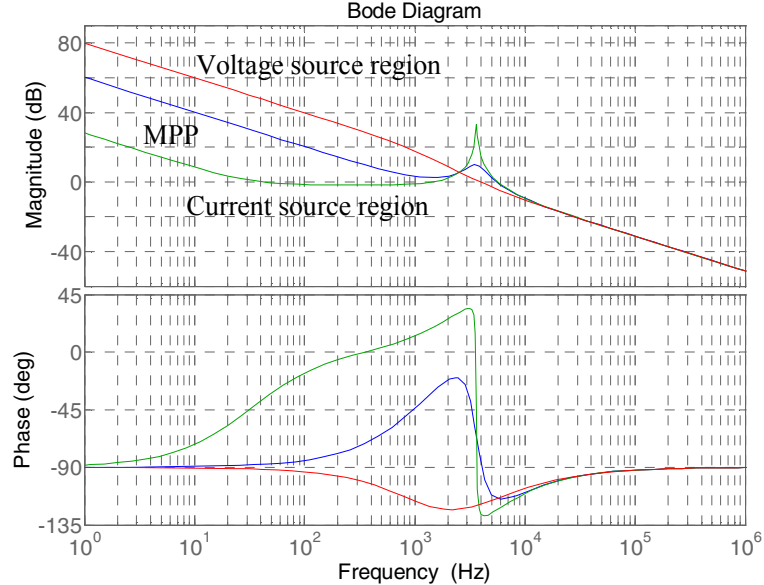

Figure 14. Current loop gain for different operating points of the PV panel

The voltage loop compensation (33) is designed to behave as an ideal integrator. This is achieved by inserting a pole $\left(R_{9}, C_{2}\right)$ at the same frequency as the zero formed by $R_{10}, C_{3}$.

$$
C_{v}=\frac{1}{R_{10} C_{3}} \cdot \frac{1}{s} \cdot \frac{\left(1+R_{10} C_{3} s\right)}{\left(1+R_{9} C_{2} s\right)}
$$

A voltage divider is used for the voltage conditioning gain $\left(H_{v}\right)$ to adapt the signal level of the PV output voltage to the error amplifier. The voltage loop gain is given by (34).

$$
T_{v}=C_{v} \cdot G_{i, c l} \cdot G_{v i} \cdot H_{v}
$$

Fig. 15 shows the voltage loop gain for different operating points of the PV panel. When the system operates at the maximum point the crossover frequency is $1.33 \mathrm{kHz}$ with a phase margin of $76^{\circ}$. In the current source region the crossover frequency is around $1.55 \mathrm{kHz}$ with a phase margin of $57^{\circ}$. In the voltage source region the crossover frequency goes down to $145 \mathrm{~Hz}$ and the phase margin is $99^{\circ}$.

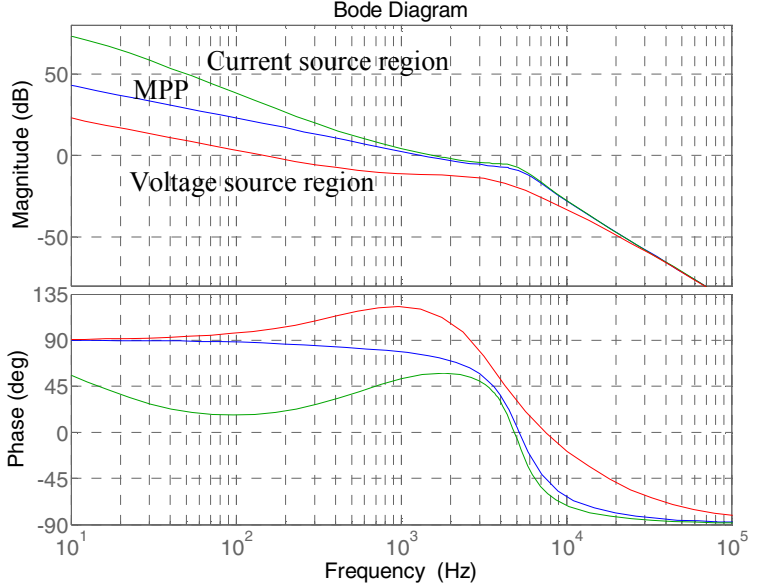

Figure 15. Voltage loop gain for different operating points of the PV panel

TABLE V

LIST OF CONTROL CIRCUITRY COMPONENTS

\begin{tabular}{cc}
\hline \hline$R_{11}$ & $1.8 \mathrm{k} \Omega$ \\
$R_{12}$ & $10 \mathrm{k} \Omega$ \\
$R_{3}, R_{7}$ & $100 \mathrm{k} \Omega$ \\
$R_{4}$ & $910 \mathrm{k} \Omega$ \\
$R_{5}$ & $51 \mathrm{k} \Omega$ \\
$R_{6}$ & $470 \mathrm{k} \Omega$ \\
$R_{8}$ & $19 \mathrm{k} \Omega$ \\
$R_{9}, R_{10}$ & $47 \mathrm{k} \Omega$ \\
$C_{1}, C_{2}, C_{3}$ & $2.2 \mathrm{nF}$ \\
Operational amplifiers & $T S V 632$ \\
Current sensor & $A C S 710$ \\
PWM controller & $T L 494$ \\
\hline \hline
\end{tabular}

Fig. 16 shows the calculated and simulated closed loop transfer function at the MPP. Fig. 17 presents the step response at the MPP calculated by using MATLAB. 


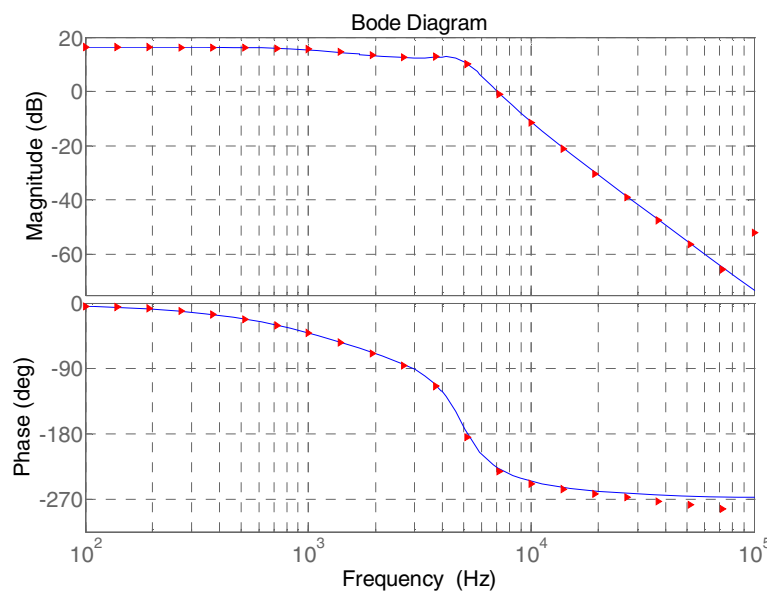

Figure 16. Closed loop transfer function in MATLAB (blue line) and LTspice (red dots) for the PV panel linearized at the MPP

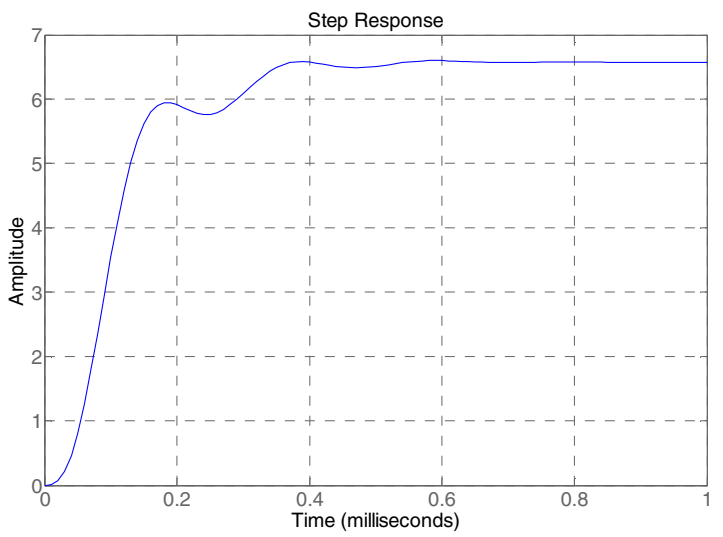

Figure 17. Calculated input voltage step response to a $1 \mathrm{~V}$ reference change for the PV panel linearized at the MPP

The calculated closed loop transfer function (35) shows very close match with the simulation. The system presents a bandwidth of $1.9 \mathrm{kHz}$ and a settling time of $0.5 \mathrm{~ms}(2 \%$ criterion).

$$
G_{v, c l}=\frac{\left(1-C_{v}\right) \cdot G_{i, c l} \cdot G_{i v}}{1-C_{v} \cdot G_{i_{c l}} \cdot G_{i v} \cdot H_{v}}
$$

\section{EXPERIMENTAL RESULTS}

A $104,4 \mathrm{~W}$ boost converter is constructed using a fast prototyping technique. The inductor is designed by using a planar magnetic core, size E32/6/20 with plate in material 3F3 from Ferroxcube. Fig. 18 shows a view of the converter prototype. Fig. 19 shows the converter steady-state operating waveforms for $V_{\text {in }}=18 \mathrm{~V}, I_{\text {in }}=5.8 \mathrm{~A}$ and $V_{\text {out }}=28 \mathrm{~V}$.

The efficiency of the power stage is measured by using a power analyzer PPA5530 from N4L. The measurement is done in open loop at $V_{\text {in }}=18 \mathrm{~V}, I_{\text {in }}=5.8 \mathrm{~A}$ and $V_{\text {out }}=30 \mathrm{~V}$. The measured converter efficiency @ $P_{\text {out }}=101,6 \mathrm{~W}$ is $97.3 \% \pm 0.2 \%$ (without accounting the losses due to the control circuitry and MOSFET gate drive).

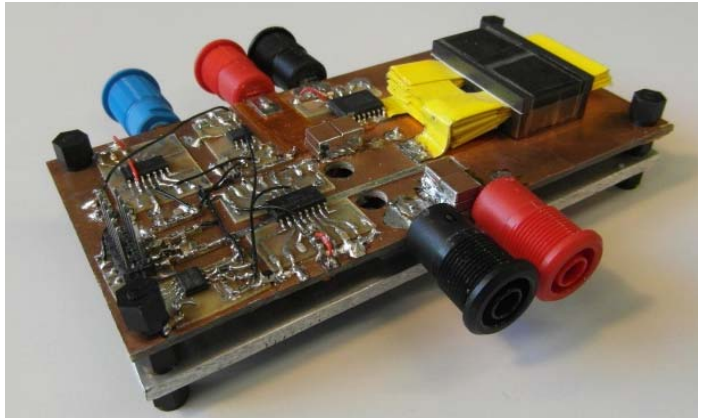

Figure 18. Boost converter with combined control loop prototype

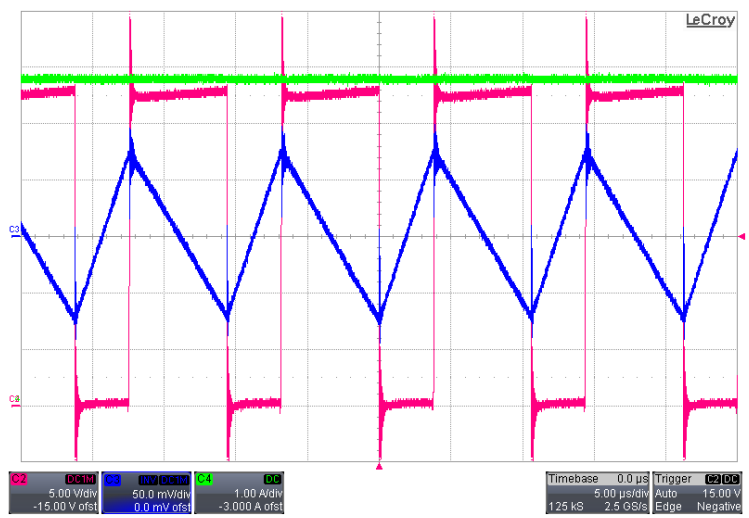

Figure 19. Converter steady-state operating waveforms. Drain to source MOSFET (red, 5V/div), input current (green, 1A/div) and inductor ripple (blue, $500 \mathrm{~mA} / \mathrm{div}$ ). Time scale 5 us/div

In order to verify the control loop design, a measurement of the loop gain is performed by using a frequency response analyzer N4L PSM1735. In order to simulate the operating conditions of the photovoltaic panel at the maximum power point, the measurements are executed by using a voltage source $\left(V_{g}\right)$ with a series resistance $\left(R_{g}\right)$. This set up allows to linearize the $I-V$ PV panel curve around the MPP. The converter operating conditions during the measurement are: $V_{g}=38.02 \mathrm{~V}, \quad R_{g}=3.43 \Omega, \quad V_{\text {bat }}=28.35 \mathrm{~V}$ and $I_{\text {in }}=5.8 \mathrm{~A}$. Fig. 20 shows the measured loop gain transfer function (red line) and the calculated transfer function (blue line). It can be observed that the calculated crossover frequency $(1.33 \mathrm{kHz})$ matches perfectly with the measurement.

Hill-climbing MPPT algorithms continuously perturb the reference, causing the PV voltage to fluctuate even if the irradiance and temperature are constant. The time between perturbations should be long enough so that the converter reaches steady-state operation. The tracking performance of the control loop is tested (Fig. 21) by perturbing the reference signal every $2.5 \mathrm{~ms}$. The amplitude of the perturbation is selected to be $160 \mathrm{mV}$, which corresponds to $1 \mathrm{~V}$ step change in the PV panel. Note that the small slopes observed in the signals are a result of the measurement being performed with ac coupling in all the oscilloscope channels. 


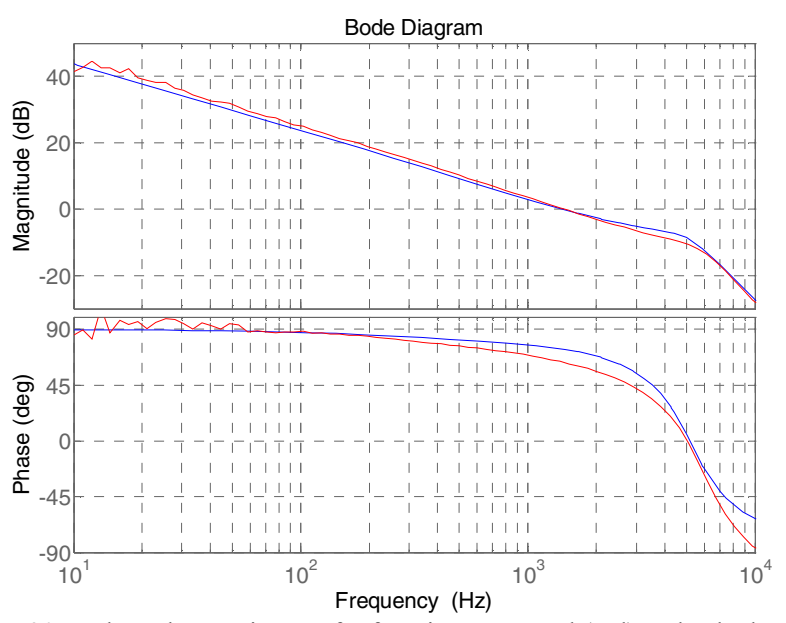

Figure 20. Voltage loop gain transfer function measured (red) and calculated (blue)

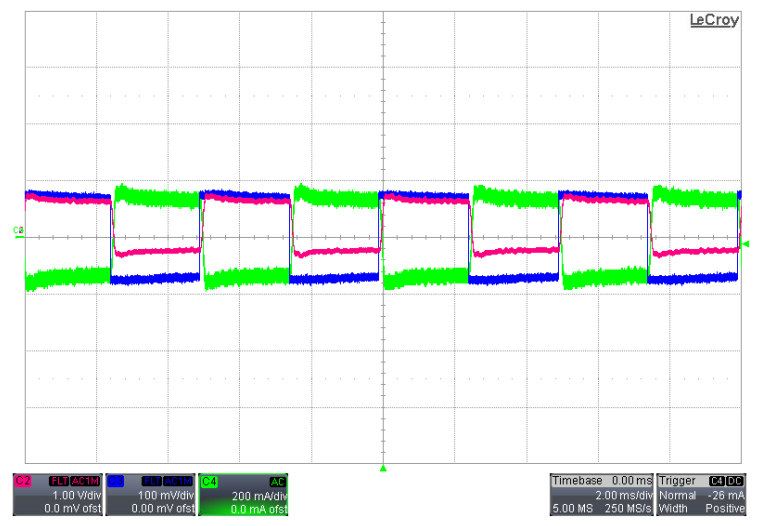

Figure 21. Voltage loop reference tracking. Reference signal (blue line, $100 \mathrm{mV} / \mathrm{div}$ ), input current (green line, $200 \mathrm{mV} / \mathrm{div}$ ) and input voltage (red line, $1 \mathrm{~V} / \mathrm{div})$. Time scale $2 \mathrm{~ms} / \mathrm{div}$

The converter stabilizes around $0.6 \mathrm{~ms}$, as shown in Fig. 21. Compared with the control scheme presented in [11], where the converter operating point is perturbed every $25 \mathrm{~ms}$, this fast time response brings several benefits to the MPPT capabilities of the converter. First, the amplitude of the perturbation can be adjusted to achieve fast tracking during fast changing irradiation conditions, while maintaining a small error in steady-state conditions. Second, under partial shading conditions, the fast tracking capabilities will allow to perform very fast sweeps over the whole PV panel $I-V$ curve to determine the position of the maximum power point. In this way, the amount of wasted energy during the sweep is minimized.

\section{CONCLUSION}

A boost converter with input voltage control for photovoltaic applications is designed and tested. The PV output voltage is selected to be the control variable because it presents small variations with changes in irradiation. In order to obtain a fast dynamic response of the converter, a double control loop is implemented. The system controls the input voltage of the converter by regulating the mean value of the inductor current. By including the inner current loop with higher crossover frequency, the overall system presents a faster response. This helps to avoid propagating load perturbations to the photovoltaic panel side. The mathematical model obtained by average state-space modeling shows a very close match to the measured loop gain transfer function. The converter control scheme plays an important role in the performance of MPPT algorithms. The designed control loop allows the system to be perturbed every $1 \mathrm{~ms}$, which enhances the converter maximum power point tracking capabilities.

\section{REFERENCES}

[1] L. Antonio and . S. Hegedus, Handbook of photovoltaic science and engineering, 2003.

[2] T. Esram and P. L. Chapman, "Comparison of photovoltaic array maximum power point tracking techniques," IEEE transactions on Energy Conversion, vol. 22, no. 2, pp. 439-449, June 2007.

[3] M. A. de Brito, L. Galotto, L. P. Sampaio, G. Melo and C. A. Canesin, "Evaluation of the main MPPT yechiniques for photovoltaic applications," IEEE transactions on Industrial Electronics, vol. 60, no. 3, pp. 1156-1167, March 2013.

[4] N. Femia, G. Petrone, G. Spagnuolo and M. Vitelli, "Optimization of perturb and observe maximum power point tracking method," IEEE transactions on Power Electronics, vol. 20, no. 4, pp. 963-973, July 2005.

[5] D. Sera, R. Teodorescu, J. Hantschel and M. Knoll, "Optimized maximum power point tracker for fast-changing enviromental conditios," in IEEE International Symposium on Industrial Electronics, 2008.

[6] A. Abdelsalam, A. M. Massoud, S. Ahmed and P. N. Enjeti, "Highperformance adaptive pertub and observe MPPT technique for photovoltaic-based microgrids," IEEE transactions on Power Electronics, vol. 26, no. 4, pp. 1010-1021, January 2011.

[7] M. G. Villalba, T. G. de Siqueira and E. Ruppert, "Voltage regulation of photovoltaic arrays: small-signal analysis and control design," IET Power Electronics, vol. 3, no. 6, pp. 869-880, November 2010.

[8] W. Xiao, W. G. Dunford, P. R. Palmer and A. Capel, "Regulation of photovoltaic voltage," IEEE Transactions on Industrial Electronics, vol. 54, no. 3, pp. 1365-1374, June 2007.

[9] M. G. Villalba and E. R. F., "Analysis and simulation of the P\&O MPPT algorithm using a linearized PV array model," in IEEE on Industrian Electronics IECON, 2009.

[10] R. D. Middlebrook and S. Cuk, "A general unified approach to modelling switching-converter power stages," IEEE Power Electronics Specialists Conference Record PESC, pp. 18-34, 1976.

[11] F. Liu, X. Duan, F. Liu, B. Liu and Y. K. , "A variable step size INC MPPT method for PV systems," IEEE transactions on Industrial Electronics, vol. 55, no. 7, pp. 2622-2628, July 2008. 